\title{
Desenho ideológico do BID: modelo de gestão no Promaben em Belém, Pará
}

\author{
Joana Valente Santana \\ Universidade Federal do Pará (UFPA)
}

Desenho ideológico do BID: modelo de gestão no Promaben em Belém, Pará

Resumo: Este artigo discute o modelo de gestão de cidades difundido pelo Banco Interamericano de Desenvolvimento (BID) para a América Latina e o Caribe, tendo como exemplo o Programa de Saneamento da Bacia da Estrada Nova (Promaben), no município de Belém, no estado do Pará. Com base no referencial da teoria social marxiana, foram pesquisados, em documentos do BID, disponíveis on-line, os projetos aprovados pelo banco em 26 países da América Latina e do Caribe, entre 1960 e 2011. Aponta a construção do desenho ideológico do BID, interligado às questões de financiamento, pobreza e meio ambiente. Recupera estudos sobre ideologia e modelo de gestão de cidades e compara analiticamente os objetivos do BID com os projetos aprovados na América Latina e no Caribe. Analisa os recursos destinados ao Promaben e reflete, que sob a aparência da diminuição da pobreza e atenção ao tema do meio ambiente, o BID prioriza os setores de projetos de infraestrutura física da cidade e projetos econômicos.

Palavras-chave: BID. Modelo de gestão. Pobreza. Meio ambiente.

Ideological Design of the IADB: Administrative Model for the Promaben Project in Belém, Pará Abstract: This article discusses the administrative model for cities promoted by the Inter-American Development Bank (IADB) for Latin America and the Caribbean, using as an example the Sanitation Program for the Estrada Nova watershed (Promaben), in the municipality of Belém, in Pará State. Based on Marxist social theory, IADB documents available on line related to projects approved by the bank in 26 Latin American and Caribbean countries from 1960 - 2011 were studied. The paper indicates the construction of an ideological design by IADB, related to the issues of financing, poverty and the environment. It reviews studies about ideology and the administrative model for cities and compares the IADB's stated objectives with the projects approved in Latin America and the Caribbean. It analyzes the resources destined to Promaben and reflects that under the appearance of decreasing poverty and attention to the environment, the IADB gives priority to physical infrastructure projects for cities and economic projects.

Keywords: IADB. Administrative Model. Poverty. Environment. 


\section{Introdução}

O Banco Interamericano de Desenvolvimento (BID) tem financiado uma quantidade expressiva de projetos para a América Latina e o Caribe em variados setores, incluindo o financiamento a projetos referentes ao desenvolvimento urbano e à moradia. Este banco justifica sua importância por ter como objetivo principal a diminuição da pobreza, especialmente a pobreza urbana, exponenciada com o crescimento das cidades e dos problemas urbanos latino-americanos. Assim, a pesquisa ${ }^{1}$, cujos resultados são apresentados neste artigo, ocupou-se de investigar a concepção de gestão de cidades, presente nos projetos urbanísticos financiados pelo BID, tomando como exemplo o Programa de Saneamento da Bacia da Estrada Nova (Promaben), na cidade de Belém, capital do estado do Pará. Cotejou o discurso com a prática de embelezamento de cidades, difundidas pelas agências multilaterais, que têm primado pela valorização da infraestruturação física dos espaços urbanos no âmbito da reprodução do capital, ampliando a negação do direito à cidade às frações de classe trabalhadora.

Estudos têm demonstrado que projetos urbanísticos financiados pelo BID resultam em uma série de problemas para os moradores removidos das áreas onde são realizadas as obras. Por outro lado, há uma clara preocupação com o aspecto da infraestrutura física dos projetos, cuja primazia requer a investigação sobre o tema do embelezamento de cidades, constituinte do modelo de gestão formatado e orientado pelo referido banco. Neste modelo, pobreza e meio ambiente são motes discursivos, enredados em uma mesma tecitura aparente (diminuição da pobreza) que escondem a necessidade da infraestrutura física das cidades para os investimentos empresariais, além da orientação para a Reforma do Estado -, articulados à retórica do desenvolvimento.

Nesta medida, este artigo busca desenvolver os argumentos teóricos em torno da categoria desenho ideológico do BID, a partir da discussão do significado do financiamento aos países da América Latina e do Caribe; do debate sobre ideologia e modelo de gestão de cidades; da apresentação e análise dos dados sobre os projetos aprovados pelo banco nessa região e, por último; da análise do Promaben, seguido das conclusões.

\section{Procedimentos metodológicos}

A investigação foi orientada pelos aportes teórico-metodológicos da teoria social marxiana, a qual oferece os insumos de apreensão e análise do objeto da pesquisa na perspectiva de totalidade ${ }^{2}$. Além da pesquisa bibliográfica, foi feito um levantamento de dados na página do BID (2011a), para investigar os projetos aprovados por setores nos 26 países da América Latina e do Caribe, no período de 1960 a 2011. Após, os dados quantitativos foram tabulados na planilha Excel e organizados na forma de gráficos e figura $^{3}$. Os dados sobre o Promaben foram adquiridos na página do BID e no portal da Prefeitura Municipal de Belém (BELÉM, 2011). Para efeito de confirmação de alguns dados documentais, foi realizada uma conversa com duas técnicas que atuam no Promaben, na cidade de Belém.

\section{A construção do desenho ideológico do BID: a questão do financiamento e os temas de pobreza e meio ambiente}

O Banco Interamericano de Desenvolvimento (BID) foi criado em 1959, a partir de uma articulação do governo brasileiro (Juscelino Kubitschek) com o governo dos Estados Unidos (Dwight Eisenhower) diante da ameaça do avanço do socialismo, na época da Guerra Fria. O financiamento inicial destinava-se ao crescimento econômico dos países considerados atrasados (propícios à aceitação das ideias comunistas), mediante o combate à pobreza, com base na concepção desenvolvimentista (e regional) (SANTANA, 2006). O banco pertence, hoje, a 48 países membros (26 países mutuários da América Latina e do Caribe e 22 não mutuários). O poder de voto de cada país membro depende da subscrição de capital ordinário que cada país tenha no banco ${ }^{4}$.

A partir dos anos 1970, os bancos multilaterais passam a defender a necessidade dos ajustes estruturais, especialmente da Reforma do Estado, interligando-se ao projeto neoliberal e ao processo de acumulação flexível (SANTANA, 2006). Considera-se que os organismos multilaterais (como o Fundo Monetário Internacional (FMI), o Banco Mundial e o BID) têm atuado na coordenação política e econômica dos interesses das frações de classe dominante e correspondem, segundo Santos (2003), à "inteligência geral" do capital. Nesse sentido, o BID constrói e repassa aos governos nacionais e locais uma série de orientações de políticas econômicas e sociais através de acordos de empréstimo, na forma de modelos de gestão para esses governos 5 .

Autores como Soares (2002) e Chossudovsky (1999) têm se empenhado em discutir criticamente a questão do "atendimento à pobreza" e o tema do "desenvolvimento sustentável" (com a incorporação da agenda ambiental) no âmbito dos ajustes estruturais, constitutivos da agenda neoliberal. Articulado a essa agenda, o BID tem, atualmente, como principais metas: "prioridade à 'redução da pobreza' e à equidade social, ao 'crescimento ambientalmente sustentável', à modernização do Estado e à integração regional" 
(BID, 2011a, s/p, grifo desta autora). Todavia, a prioridade no "atendimento à pobreza e o enfoque no crescimento ambientalmente sustentável" corresponde a um discurso aparente que esconde suas determinações essenciais, a saber, a construção de um "desenho ideológico" expresso em modelos para ação, no caso da política urbana, no modelo de gestão de cidades. Modelo que orienta, aparentemente, a elaboração de projetos sociais de moradia para as frações de classe trabalhadora, mas que, na verdade, esconde a prioridade na infraestruturação física das cidades. São, assim, facilitados os investimentos capitalistas, fragilizando o direito à cidade pelas frações de classe dominada.

\section{Notas sobre ideologia e modelo de gestão de cidades}

Milton Santos (2003, p. 53, grifos do autor) afirma que na fase atual do capitalismo, onde há a imperiosa defesa do mercado como solução única para a produção da vida (pensamento único), a "ideologia" é fundamental para a produção, difusão, reprodução e conservação dessa defesa.

Nas condições atuais, a ideologia é reforçada de uma forma que seria impossível ainda há um quarto de século, já que, primeiro as ideias e, sobretudo, as ideologias se transformam em situações, enquanto as situações se tornam em si mesmas 'ideias', 'ideias do que fazer', 'ideologias' e impregnam, de volta, a ciência (que santifica as ideologias e legitima as ações), uma ciência cada vez mais redutora e reduzida, mais distante da busca da 'verdade' [...].

A ideologia tomada como "distorção da realidade" renova-se substancialmente no âmbito conceitual (teórico) e no terreno da história (prática). Teoria e prática ideológica que acompanham o movimento da sociedade e a defesa da ordem burguesa, a exemplo da ideologia liberal, desenvolvimentista, do desenvolvimento sustentável, da ideologia neoliberal, ideologia pós-moderna ${ }^{7}$ e mais recentemente, da ideologia neodesenvolvimentista.

Konder (2003, p. 248) demonstra que o "campo onde a ideologia manifesta mais explicitamente seu poder de inviesamento é, com certeza, o campo da atividade política". Com base no pensamento de Gramsci, Coutinho (2006) aponta elementos importantes para apreensão da relação entre ideologia e Estado. Nesta medida, o Estado, em sentido amplo, é constituído de duas esferas: 1) a "sociedade política" (onde o Estado em sentido estrito exerce a coerção) e; 2) a "sociedade civil", formada pela totalidade das organizações que elaboram e/ou difundem as ideolo- gias. Entretanto, assinala Coutinho, embora Gramsci faça a distinção entre as duas esferas, existe uma unidade, visto que a supremacia de um grupo social se realiza de duas formas como "domínio" e como "direção intelectual e moral"". A partir dessa observação, Coutinho (2006, p. 40) destaca o "papel das ideologias", ou melhor, das "disputas ideológicas no interior do próprio Estado”, especialmente visualizadas nas sociedades modernas. Pode-se considerar, a partir das análises de Coutinho, que os organismos multilaterais, particularmente o Banco Interamericano de Desenvolvimento, correspondem a um momento da sociedade civil no papel de formatar e de disseminar um discurso ideológico na defesa da ordem burguesa que é, no caso da política urbana, expresso através da formulação e da disseminação do modelo de gestão de cidades.

O modelo de gestão de cidades a que se está fazendo referência vem sendo discutido por diversos autores, como Vainer (2002), Harvey (1996), dentre outros. As opiniões desses autores giram em torno dos seguintes argumentos: no processo atual de acumulação do capital, as cidades passam a ter um papel importante na lógica da produção e reprodução das relações sociais capitalistas. Desenvolve-se a ideia de competitividade entre os lugares, onde as cidades devem ser eficientes e atrativas aos investimentos capitalistas. Para tanto, é fundamental que as cidades sejam administradas eficientemente, daí a necessidade de uma gestão de cidades onde a dimensão técnica sobreponha-se à dimensão política, com a consequente diminuição das possibilidades de efetivação dos direitos de cidadania. $\mathrm{O}$ esforço das agências multilaterais, e em particular do BID, é de propagar modelos que sirvam ao planejamento urbano, baseados na racionalidade de gestão técnica, que busque ampliar a capacidade gerencial, especialmente da administração local ${ }^{9}$.

Além desses argumentos, cabe ainda ressaltar, que, na constituição do modelo de gestão de cidades, o enfoque à administração local não é aleatória. Articulado ao dogma neoliberal, a lógica imanente nas orientações do BID é que os governos nacionais devem ser liberados das responsabilidades com as políticas sociais, tendo em vista que devem se ocupar da direção macroeconômica nacional e de prover investimentos de infraestrutura de grande porte (o Programa de Aceleração do Crescimento PAC, no Brasil, é expressivo dessa orientação). Por esse motivo, os governos locais devem ter a responsabilidade da implementação das políticas sociais focalizadas nos pobres, com atenção ao tema do meio ambiente, além de preocupar-se em executar projetos urbanísticos de infraestruturação das cidades ${ }^{10}$ que facilitem os investimentos empresariais (SANTANA, 2006). 
3 Desvelando o desenho ideológico: entre os objetivos pretendidos e os projetos aprovados pelo BID na América Latina e no Caribe

O desenho ideológico do Banco Interamericano de Desenvolvimento pode ser desvelado quando se observam os projetos aprovados para financiamento nos países da América Latina e do Caribe. Os dados investigados ratificam a noção, antes apresentada, de que os bancos multilaterais atuam como inteligência geral do capital (SANTOS, 2003). Foram levantados os dados sobre projetos aprovados (com um total de 16.297 projetos), por setores, em países membros (mutuários) da América Latina, no período de 1960 a 2011. Em relação aos setores de projetos aprovados, a investigação aponta a prioridade do BID no setor de "Reforma e modernização do Estado" (15\%), conforme o gráfico 1. A prioridade no tema da Reforma do Estado, pelo BID, sem dúvida, corrobora a análise de que os bancos multilaterais contribuem na formação das orientações econômicas e das políticas mundiais. A Reforma do Estado, que implica em políticas sociais mínimas, agrava as expressões da questão social, o que contradiz o discurso do banco, quando aponta ser a diminuição da pobreza seu objetivo central.

Gráfico 1: Projetos aprovados pelo BID por setores na América Latina e no Caribe (19602011)

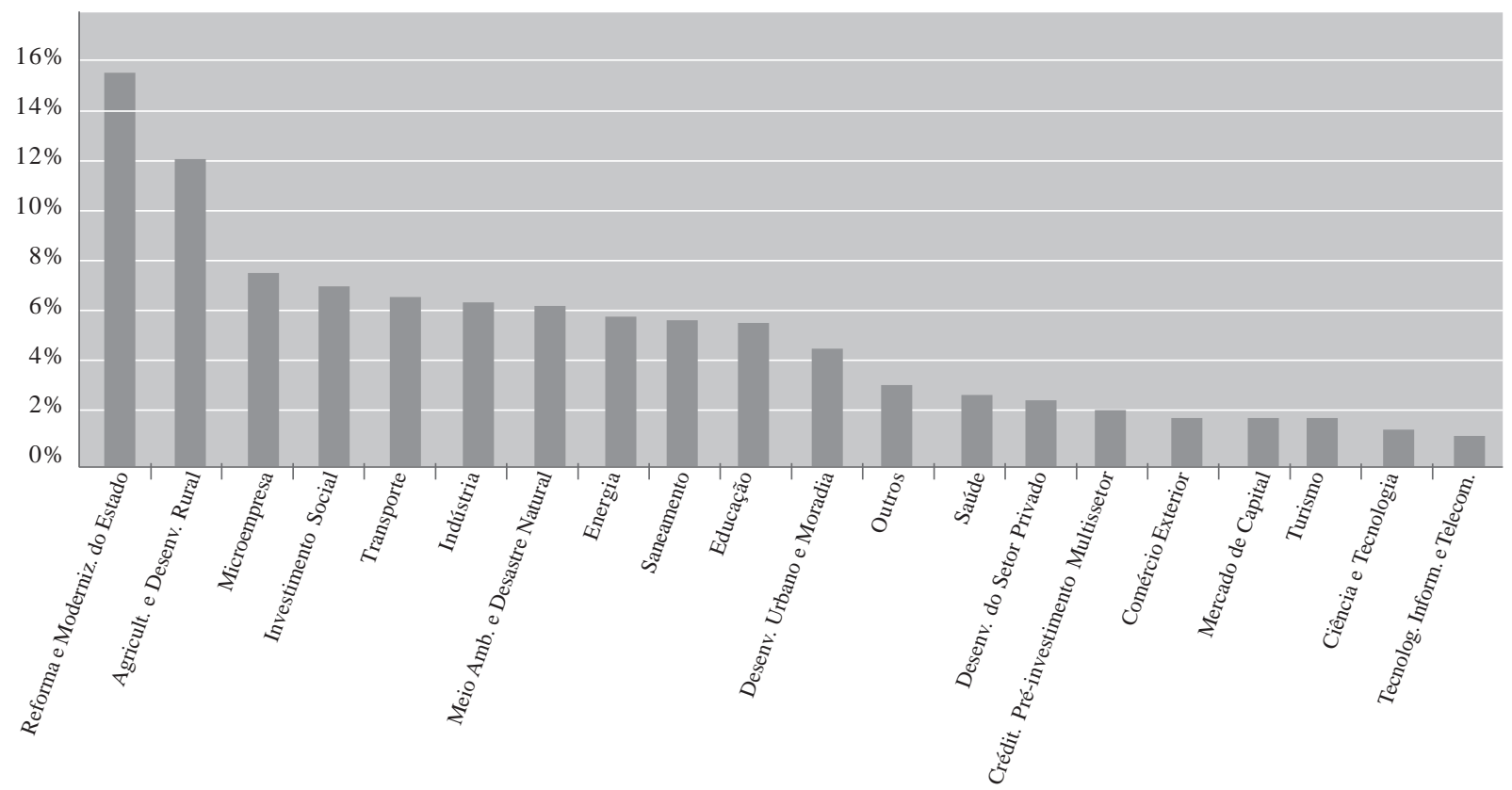

Fonte: Elaboração própria. Montado a partir de BID (2011a). Dados de 21 de junho de 2011.

Gráfico 2: Projetos aprovados pelo BID por setores agrupados na América Latina e no Caribe (1960-2011)

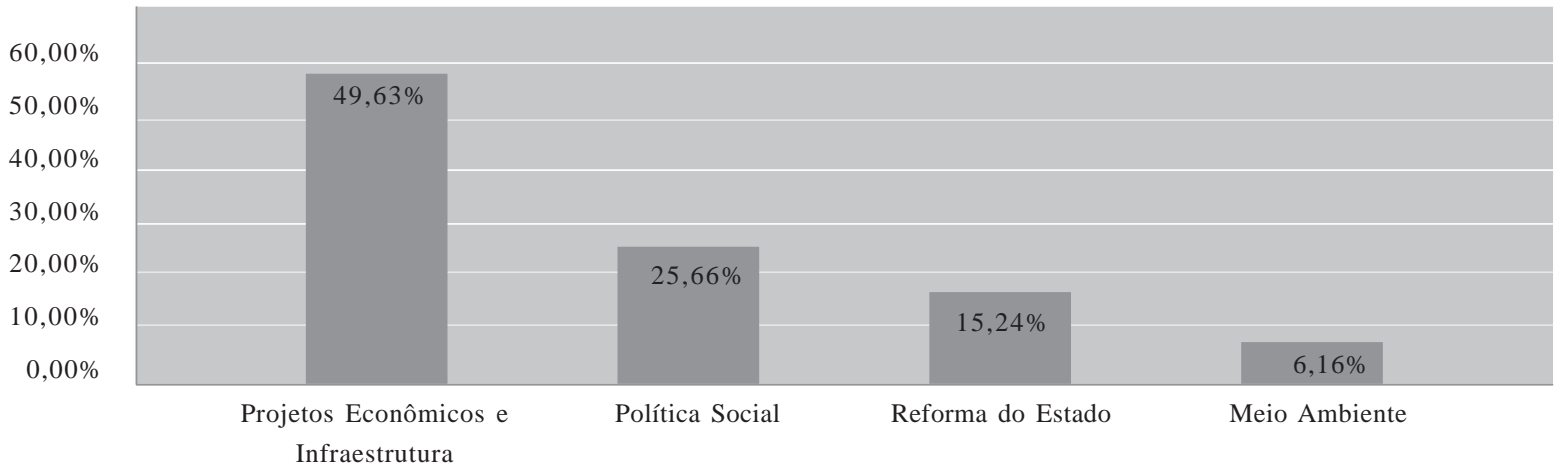

Fonte: Elaboração própria. Montado a partir de BID (2011a). Dados de 21 de junho de 2011. 
No sentido de maior aproximação da lente da pesquisa ao objeto estudado, os setores de projetos aprovados pelo Banco foram agrupados em quatro variáveis investigativas ${ }^{11}$, a serem cotejadas com os "objetivos, metas e prioridades" do banco. Os resultados demonstram que, no período de 1960 a 2011, os setores agrupados em "Projetos Econômicos e Infraestrutura" correspondem a 49,63\% do total dos projetos aprovados, seguidos dos projetos referentes à "Política Social" (25,66\%), "Reforma do Estado" $(15,24 \%)$ e, por último, "Meio Ambiente", (6,16\%), conforme gráfico 2. Por seu turno, a figura 1 apresenta esse panorama para os países da América Latina e do Caribe. jetos econômicos e de infraestrutura, que se interligam ao tema da integração regional.

\section{Programa de Saneamento da Bacia da Estrada Nova: o modelo de gestão do BID em prática}

Na cidade de Belém do Pará está sendo executado um projeto urbanístico financiado pelo BID, denominado Programa de Saneamento da Bacia da Estrada Nova (Promaben), sob a responsabilidade da Prefeitura Municipal de Belém ${ }^{12}$. Essa Bacia é uma das maiores de Belém e possui aproximadamente 220 mil habitantes, onde cerca de 3 mil famílias vivem

Figura 1: Projetos aprovados pelo BID por setores e países na América Latina e no Caribe (1960-2011)

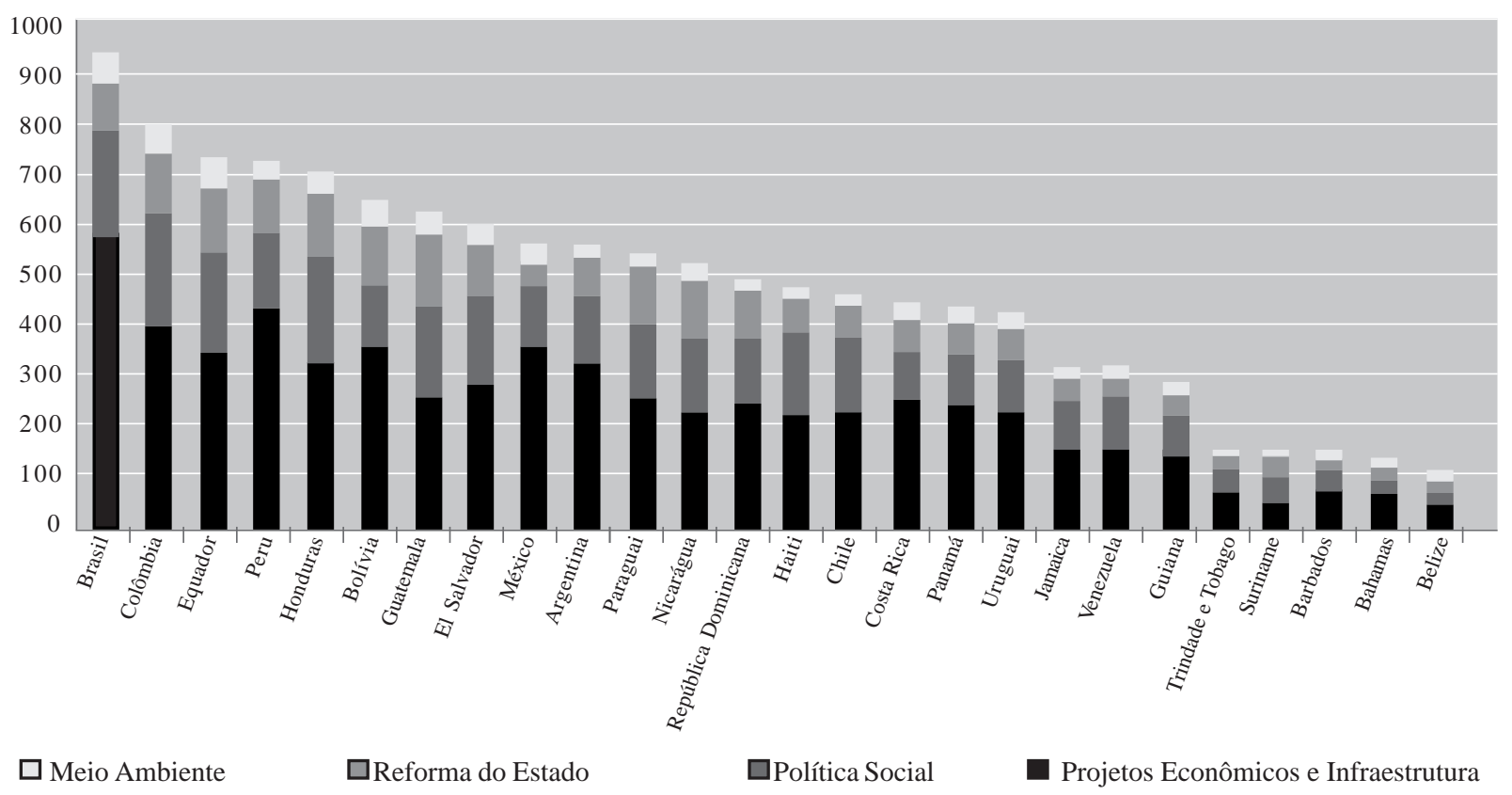

Fonte: Elaboração própria. Montado a partir de BID (2011a). Dados de 21 de junho de 2011.

Se forem cotejados os objetivos, metas e prioridades do BID, a saber: "prioridade à redução da pobreza e à equidade social, ao crescimento ambientalmente sustentável, à modernização do Estado e à integração regional", com os dados apresentados no gráfico 2 e na figura 1, é possível verificar como, efetivamente, os setores de política social e meio ambiente (apontados como os dois primeiros objetivos do banco) são tratados em segundo e último planos, respectivamente, quando se trata da aprovação dos projetos. Desta forma, o BID tem contribuído para o processo de produção e reprodução do capital - utilizando discursivamente o tema da pobreza e meio ambiente - apoiando os setores vinculados aos pro- em condições precárias de moradia relacionadas a saneamento básico e ambiental, água e eletricidade, coleta de lixo, esgotamento sanitário, sistema de drenagem, dentre outros ${ }^{13}$ (BID, 2007).

Os objetivos do Promaben são: "contribuir para resolver os problemas socioambientais que afetam os habitantes da bacia da Estrada Nova de Belém, no Estado do Pará" (BID, 2009b, p. 1). Prevê uma intervenção urbanística nos principais canais das quatro sub-bacias da Estrada Nova, cuja intervenção está agrupada em quatro componentes: melhoria da drenagem urbana, infraestrutura viária, infraestrutura sanitária e sustentabilidade social e institucional (BID, 2009b). Para a execução das obras está previsto o 
reassentamento de cerca de 1.100 famílias e aproximadamente 150 microempresas familiares ${ }^{14}$.

O custo total do programa é estimado em US\$ 137.500 milhões, sendo US\$ 68.750 milhões financiados pelo BID, e a outra parte (US\$ 68.750 milhões) corresponde à contrapartida da Prefeitura Municipal de Belém (BID, 2009a). No que se refere à previsão orçamentária, a análise de uma tabela de custos referentes ao componente do programa, e disponível em um documento da Prefeitura de Belém, é expressiva para desvelar o aspecto discursivo sobre o modelo de gestão de cidades orientado pelo BID e efetivado pelo Estado, conforme, se pode verificar na tabela 1. $\operatorname{tal}^{17}$. Isso demonstra o tamanho da desigualdade na opção entre a infraestrutura física e a infraestrutura social e ratifica o aspecto discursivo em relação ao tema da diminuição da pobreza e atenção ao meio ambiente em projetos urbanísticos financiados pelo BID. Por outro lado, observa-se o que contém o Plano Diretor do Processo de Relocalização de População e Atividades Econômicas (do Promaben) em relação aos objetivos gerais das "normas e critérios para relocalização de população e atividades econômicas":

As áreas interferentes com as obras de implantação da macrodrenagem e as demais obras que visam a 'requalificação urbana e ambiental' na bacia

Tabela 1: Estimativa de custos por componentes do Promaben - Sub-bacias 01, 02, 03 e 04

\begin{tabular}{|l|c|c|}
\hline \multicolumn{1}{|c|}{ Componente } & $\begin{array}{c}\text { Valor Absoluto } \\
\text { (valores em R\$ 1.000) }\end{array}$ & $\%$ \\
\hline 1. Drenagem urbana & 186.440 & 35,01 \\
\hline 2. Abastecimento de água & 10.000 & 1,88 \\
\hline 3. Esgotamento sanitário & 122.910 & 23,08 \\
\hline $\begin{array}{l}\text { 4. Urbanização: vias urbanas (21.760); obras de arte (21.440); } \\
\text { projeto urbanístico (24.000); orla (125.000) }\end{array}$ & 192.200 & 36,09 \\
\hline $\begin{array}{l}\text { 5. Demais componentes do programa Limpeza urbana (7.100); } \\
\text { fortalecimento institucional (1.800); Desapropriação/ } \\
\text { reassentamento (10.800); educação ambiental (1.200) }\end{array}$ & 20.900 & 3,92 \\
\hline Total & & $\mathbf{1 0 0 , 0 0}$ \\
\hline
\end{tabular}

Fonte: Elaboração própria. Montado a partir dos dados disponíveis em Belém (2007, p. 34).

Os dados a serem comentados são, sem dúvida, os componentes 4 e 5 da tabela 1 . A observação a ser feita refere-se à disparidade na previsão de gastos entre os projetos de infraestrutura e os de gastos efetivos com a questão da moradia e ambiental. Isso porque o componente urbanização (item 4 da tabela 1), que inclui os serviços de infraestrutura e de orla ${ }^{15}$, tem a maior previsão de gastos $(36,09 \%)$. Para os demais componentes do programa, que incluem, dentre outros, a desapropriação/reassentamento de famílias e educação ambiental, estão previstos apenas $3,92 \%$. Uma observação mais atenta demonstra que, em relação ao total de gastos, o item orla tem a maior destinação de recursos quando comparado a todos os demais itens constitutivos dos componentes do Programa ${ }^{16}$. Enquanto isso, a previsão de gastos com a desapropriação/reassentamento de famílias equivale, em relação ao total, a apenas $2,02 \%$, e o item educação ambiental, a apenas $0,22 \%$ desse to- de Estrada Nova deverão 'estar livres da ocupação antrópica desordenada'. O objetivo geral deste Programa de Remoção e Reassentamento ‘é liberar estas áreas para implantar tais obras' considerando o resgate da cidadania como condição para a sustentabilidade do Promaben (BELÉM, 2007, p. 93, grifo desta autora).

Este trecho revela os pontos centrais do modelo de gestão de cidades em discussão: é preciso retirar as pessoas dos locais insalubres ("estar livres da ocupação antrópica desordenada"), reassentálas para lugares possíveis (em geral inadequados às necessidades das famílias) e reconstruir o espaço com intervenções urbanísticas visando o embelezamento da cidade, a ser consumida por quem tem poder aquisitivo. Estudos sobre impactos socioeconômicos na vida de famílias removidas têm demonstrado uma série de perdas (acesso ao tra- 
balho, diminuição de renda, espaço inadequado da nova moradia, perda nas relações de vizinhança, pagamento de taxas e serviços, antes inexistentes). Nos documentos oficiais (do BID e da Prefeitura de Belém) sobre reassentamento involuntário de famílias, "o tratamento sobre a questão da permanência de famílias reassentadas é quase nulo", significando que o Programa de Saneamento da Estrada Nova deverá reproduzir a tendência de impermanência de famílias após o reassentamento, resultando em perdas para frações da classe trabalhadora.

$\mathrm{Na}$ visita in loco ao Promaben, foi possível visualizar a situação dos canais da Bacia da Estrada Nova (Bernardo Sayão, Timbiras, Quintino, Caripunas) onde vivem inúmeras pessoas em condições de precariedade habitacional (casas em cima de pequenos rios poluídos, próximas ao lixo e carência de esgoto sanitário). Também foi possível perceber as obras em andamento com pessoas já retiradas dos canais e parte da orla preparada e infraestruturada com acesso ao rio. A projeção de imagens no futuro, feita pelo projeto, apresenta a orla arborizada, com equipamentos e rede de serviços, quiosques, restaurantes; uma imagem de cidade embelezada, sem os moradores pobres e sem os conflitos sociais. Espaço propício ao turismo e aos investimentos empresariais, expressando o significado do modelo de gestão de cidades no contexto do desenho ideológico do BID.

\section{Conclusão}

O escritor português José Saramago ([20-?], online), em vídeo publicado na internet, ao tratar sobre a democracia disse:

As grandes decisões são tomadas numa outra esfera [...] as grandes organizações financeiras internacionais, os FMI's, as Organizações Mundiais do Comércio, os Bancos Mundiais, a OCDE [...] nenhum desses organismos é democrático [...]. Como podemos continuar a falar de democracia se aqueles que efetivamente governam o mundo não são dirigidos e eleitos democraticamente pelo povo? Quem é que escolhe os representantes dos países nessas organizações? [...].
Essa reflexão é pertinente para a apreensão do poder de comando da economia capitalista, articulada à esfera política. Esse poder é produzido e veiculado pelos organismos internacionais (como o FMI, Banco Mundial e o BID), sendo absolutamente ligado à necessidade de produção, distribuição e consumo de mercadorias e ao mundo das finanças capitalistas.

Nesse particular, o BID tem construído um "desenho ideológico" voltado aos países da América Latina e do Caribe e articulado em torno do modelo de gestão de cidades. Os núcleos constitutivos desse desenho ideológico são: a reforma do Estado, a infraestrutura física (de grande e pequeno porte) e projetos econômicos e os temas de pobreza e meio ambiente.

O primeiro núcleo é preponderante e central. A reforma e modernização do Estado é orientada: a) para o Estado-nação que deve se ocupar dos assuntos macroeconômicos (serviços da dívida, metas de inflação e infraestrutura de grande porte) e; b) para os governos locais, que devem gerir políticas sociais mínimas e compensatórias e, ao mesmo tempo, destinar recursos para a infraestrutura física das cida des. Esse primeiro núcleo é constitutivo do discurso e da prática neoliberal. Os dados apontados no gráfico 1 expressam a preponderância do tema da reforma do Estado no interior do BID.

$\mathrm{O}$ segundo núcleo refere-se à premência da infraestrutura física das cidades, articulada a projetos econômicos, tal como apresentado no gráfico 2 e figura 1. Os dados servem para desvelar a engrenagem ideológica do banco que, sob a aparência "da melhoria ambiental e melhoria da qualidade de vida das pessoas pobres", esconde a necessidade de infraestruturação física do espaço urbano, para usar a argumentação de Harvey (2005), voltada à produtividade capitalista ${ }^{18}$.

$\mathrm{O}$ núcleo concernente à pobreza constitui-se no elemento mais aparente ${ }^{19}$ do BID. Do ponto de vista do discurso ideológico, o objetivo principal do banco é a diminuição da pobreza, com melhoria na qualidade de vida, geração de renda, dentre outros. Todavia, os números evidenciados no gráfico 2 e na figura 1 negam essa assertiva. O estudo da lógica e da operacionalidade dos projetos de moradia (a exemplo do Promaben) evidencia o significado do modelo de gestão orientado pelo BID e aplicado, com anuência do Estado, nos países latino-americanos. 
Alguns espaços da cidade são escolhidos para implantação de infraestrutura física e destinados às empresas capitalistas, ao turismo e/ou aos grandes eventos (como a Copa do Mundo). Para tanto, o Estado indeniza ou remove as pessoas pobres para conjuntos habitacionais, implicando frequentemente na piora das condições de vida dessas pessoas. Há pouca preocupação, seja do BID, seja do Estado com a permanência ou com o nível de satisfação das pessoas nas novas unidades habitacionais. Na maioria das vezes, o que permanece é a infraestrutura física e não as pessoas pobres.

O núcleo sobre meio ambiente é apontado nos resultados da pesquisa em último lugar, conforme dados do gráfico 2 e figura 1. Esse tema aparece enredado no discurso ideológico, no sentido de mitigação dos problemas ambientais e educação ambiental. A análise evidencia que é preciso educar ambientalmente os pobres que, aliás, são os "culpados" pela degradação ambiental (rios, acúmulo de lixo). Por isso, os projetos de educação ambiental "ensinam" os usuários a lidar com os novos equipamentos urbanos e a cuidar dos empreendimentos.

Nesta medida, pode-se afirmar que os núcleos constitutivos do desenho ideológico do BID (articulado ao modelo de gestão de cidades e executados com a anuência do Estado-nação e dos governos estaduais e locais na América Latina) comportam a coerção e o consenso, para retomar a argumentação de Coutinho (2006). O Banco impõe condicionalidades aos governos ("exercita a coerção") e, ao mesmo tempo, realiza seminários e publica uma série de textos cujos conteúdos pasteurizam a realidade e apresentam as expressões da questão social de forma maquiada, de tal modo que a leitura desses textos demonstra que as pequenas ações e/ou os projetos sociais (ainda que focalizados nos pobres entre os pobres) irão lograr resultados para todos ("constrói e articula o consenso").

Sem dúvida, mesmo que a dívida seja feita e paga pelos Estados nacionais, estaduais e locais, o BID tem influência na condução das políticas urbanas. Nesse particular, os profissionais envolvidos nos projetos urbanísticos, dentre eles os assistentes sociais, são requisitados a atuar nessa engrenagem, encarando a difícil tarefa de contribuir com a remoção dos pobres, mesmo tendo clareza que esse processo vai de encontro aos avanços referentes aos direitos de cidadania. Daí a necessidade da apropriação desse complexo tema pelos profissionais de Serviço Social da área urbana, apreendendo a particularidade dessa requisição para uma atuação profissional, orientada teórica e metodologicamente em favor dos trabalhadores e articulada às demandas dos movimentos sociais pelo direito à cidade, conectando-se a projetos anticapitalistas.

\section{Referências}

BELÉM. Prefeitura Municipal de Belém, Portal, 2001. Disponível em: 〈www.belem.pa.gov.br/>. Acesso em: 6 ago. 2011.

Programa de Reabilitação Urbana e Ambiental da Bacia da Estrada Nova - Promaben. Relatório de Impacto Ambiental. Tomo 01/02, 2007. Disponível em: <http:// www.belem.pa.gov.br>. Acesso em: 25 maio 2011.

Prefeitura debate Portal da Amazônia com sociedade. Belém, 2010. Disponível em: <www.belém.pa.gov/l app/c2ms/v/apoio.php?pg=busca\&q=Prefeitura-+debate+ Portal+da+amazonia>. Acesso em: 21 jul. 2010.

BID. Banco Interamericano de Desenvolvimento. Documento Conceptual de Proyecto-Brasil (DCP). 2007. Disponível em: <http://www.iadb.org >. Acesso em: 6 maio 2011.

Contrato de empréstimo. 2009a. Disponível em: <http:/ /www.iadb.org>. Acesso em: 6 maio 2011.

Anexo Único. Promaben. 2009b. Disponível em: <http:/ /www.iadb.org >. Acesso em: 6 maio 2011.

Países membros/Nossos objetivos, metas e prioridades setoriais/Projetos aprovados. Washington D. C., 2011a. Disponível em: <http://www.iadb.org >. Acesso em: 26 set. 2011.

Presidente do BID e Presidenta Dilma Rousseff discutem agenda de trabalho do Banco no País. Plano Brasil sem Miséria, Copa 2014 e integração regional são prioridades. Washington D. C., 2011b. Disponível em: <http://www.iadb.org >. Acesso em: 4 jul. 2011.

CHOSSUDOVSKY, M. A globalização da pobreza: impactos das reformas do FMI e do Banco Mundial. Tradução de Marylene Pinto Michael. São Paulo: Moderna, 1999.

COUTINHO, C. N. O estruturalismo e a miséria da razão. Rio de Janeiro: Paz e Terra, 1974.

Intervenções: o marxismo na batalha das ideias. São Paulo: Cortez, 2006.

HARVEY, D. Do gerenciamento ao empresariamento: a transformação da administração urbana no capitalismo tardio. Tradução de Luís Octávio da Silva e Micaela Krumholz. Espaço e Debates, ano 16, n. 39, p. 48-64, 1996. 2005.

A produção capitalista do espaço. São Paulo: Annablume,

IAMAMOTO, M. V. Serviço Social em tempo de capital fetiche: capital financeiro, trabalho e questão social. São Paulo: Cortez, 2008. 
KONDER, L. A questão da ideologia. São Paulo: Companhia das Letras, 2003.

LUKÁCS, G. Marxismo e teoria da literatura. Rio de Janeiro: Civilização Brasileira, 1968.

História e consciência de classe. Porto: Escorpião, 1974.

MARX. K.; ENGELS, F. A ideologia alemã. In: FERNANDES, F. (Org.). Marx e Engels. São Paulo: Ática, 1989, p. 182-214.

PAULO NETTO, J. Marxismo impenitente. Contribuição à história das ideias marxistas. São Paulo: Cortez, 2004.

ROJAS, E. Los desafíos de un continente urbano. La acción del BID en desarrollo urbano. División de Programas Sociales. Departamento de Desarrollo Sostenible. Washington, D.C.: Banco Interamericano de Desarrollo, 2004.

SANTANA, J. V. Banco Interamericano de Desenvolvimento e Política Urbana no município de Belém: tensões e compatibilidades no modelo de gestão de cidades e no discurso da participação social. 320 f. 2006. Tese (Doutorado em Serviço Social) - Escola de Serviço Social, Universidade Federal do Rio de Janeiro, 2006.

SANTOS, M. Por uma outra globalização: do pensamento único à consciência universal. Rio de Janeiro: Record, 2003.

SARAMAGO, J. A democracia por José Saramago. [20-?]. Vídeo (2 min.). Disponível em: <http://www.youtube.com/ watch?v=HRX5j9OYrrE $>$. Acesso em: 6 out. 2011.

SOARES, L. T. Os custos sociais do ajuste neoliberal na América Latina. São Paulo: Cortez, 2002. (Coleção Questões da nossa época, v. 78).

VAINER, C. B. Pátria, empresa e mercadoria. Notas sobre a estratégia discursiva do planejamento estratégico urbano. In: ARANTES, O.; VAINER, C. B.; MARICATO, E. (Org.). A cidade do pensamento único: desmanchando consensos. Petrópolis: Vozes, 2002, p. 75-203.

\section{Notas}

1 Projeto de pesquisa intitulado: Banco Interamericano de Desenvolvimento e modelo de gestão de cidades: estudo da lógica e intervenção urbanística em Belém (Brasil) e Buenos Aires (Argentina), desenvolvido em nível de pós-doutorado no Centro de Investigaciones Habitat y Município, da Facultad de Arquitectura, Diseño y Urbanismo, da Universidad de Buenos Aires (Argentina), com Bolsa da CAPES (Programa de Estágio Pós-Doutoral no Exterior., Processo número 1532/11-1). Dados os limites do artigo, serão apresentados - como exemplo de projeto urbanístico somente os dados de Belém (Brasil).
2 O esclarecimento do método de investigação é importante tendo em vista que o construto pós-moderno, tão em voga na academia, tem jogado forte papel no sentido de desconstruir análises baseadas no método dialético que buscam apreender a totalidade dos fenômenos. Como afirma Coutinho (2006, p. 113, grifo do autor): "Afirma-se agora que o ponto de vista da totalidade está superado, que os 'grandes relatos' não têm mais sentido [...], que as lutas não devem ser travadas em prol de valores universais e, sim, da afirmação das identidades e das diferenças [...]. Com maiores ou menores mediações, ochamado pós-modernismoé a superestruturaideológica da contrarreforma neoliberal." Daí ser pertinente relembrar as argumentações de Lukács (1974, p. 15-16, grifo do autor), quando diz: "O marxismo ortodoxo não significa, pois, uma adesão sem crítica aos resultados da pesquisa de Marx [...] ortodoxia em matéria de marxismo refere-se, pelo contrário, e exclusivamente, ao 'método",.

3 Esses dados não estão disponíveis na página do BID na forma de tabelas ou gráficos. Foram adquiridos e compilados a partir de pesquisa on-line de cada setor, por país.

4 Países membros mutuários: Argentina, Bahamas, Barbados, Belize, Bolívia, Brasil, Chile, Colômbia, Costa Rica, El Salvador, Equador, Guatemala, Guiana, Haiti, Honduras, Jamaica, México, Nicarágua, Panamá, Paraguai, Peru, República Dominicana, Suriname, Trinidad e Tobago, Uruguai, Venezuela. Países membros não mutuários: Alemanha, Áustria, Bélgica, Canadá, Croácia, Dinamarca, Eslovênia, Espanha, Estados Unidos, Finlândia, França, Israel, Itália, Japão, Noruega, Países Baixos, Portugal, Reino Unido, República da Coreia, República Popular da China, Suécia, Suíça. Os países mutuários têm 50,02\% do poder de voto na diretoria do banco. Canadá e Estados Unidos têm 34,01\% e os demais países, 15,98\% (BID, 2011a). Vale destacar que os Estados Unidos possuem o maior capital $(30,01 \%)$. Brasil e Argentina são os segundos maiores acionistas, com 10,75\% de capital, cada um.

5 O BID formula para cada país da América Latina e do Caribe uma série de estudos e orientações de políticas nos denominados Documentos de País e de Estratégia, onde são definidas as estratégias do banco em vários setores de políticas. Como afirma Iamamoto (2008, p. 435, grifo da autora): os "organismos multilaterais, como o 'Banco Mundial (BIRD)' e 'Banco Interamericano de Desenvolvimento (BID)' que junto com o 'Fundo Monetário Internacional (FMI)' centralizam as mais importantes decisões econômicas, políticas e jurídicas planetárias. Estas organizações integram o núcleo que traça as diretrizes políticas para os Estados nacionais, processo esse legitimado pelos governos, que participam da elaboração das propostas e/ou as referendam."

6 Segundo Konder (2003), Marx identifica que uma "construção teórica distorcida", mesmo ligada a uma situaçãohistórica que legitima essa distorção, representa uma ideia que articula a "ideologia à alienação".

7 Não é possível tratar do debate conceitual de cada perspectiva ideológica nos níveis teórico e histórico, dado os limites desse artigo. Mas é possível identificar, através da produção de teóricos críticos, 
o significado e a denúncia da utilização da ideologia no processo histórico de conservação da ordem burguesa. Nessa linha, encontram-se os argumentos de Marx e Engels em relação ao pensamento dos neo-hegelianos (MARX; ENGELS, 1989); a constatação de Lukács sobre a "decadênciaideológica do pensamento burguês" moderno pós 1848 (LUKÁCS, 1968); a importante discussão de Coutinho sobre o empobrecimento do pensamento racional moderno (a "miséria da Razão") em substituição à Razão dialética (COUTINHO, 1974); o riquíssimo trabalho de Paulo Netto (2004) sobre o construto da pós-modernidade e a regressão do pensamento crítico moderno.

8 Assim, em Gramsci, a supremacia corresponde ao momento que unifica (sem retirar a singularidade) a "hegemonia" ea "dominação", o "consenso" e a "coerção", a "direção" e a ditadura.

9 Nesta medida, o chamado marketing urbano cresce na mesma proporção em que se solidifica esse modelo de gestão de cidades. Vejam-se, por exemplo, as disputas internacionais e interestaduais feita entre os governos nacionais e locais para sediar os eventos como a Copa do Mundo e os Jogos Olímpicos, condensando uma parceria público-privada, onde seguramente a milionária infraestrutura construída para esses eventos, inclusive com recurso dos bancos estatais (estádios, aeroportos, rede hoteleira, transporte), nãoé, de maneira nenhuma, destinada aos trabalhadores.

10 A discussão da produção da cidade capitalista e da infraestrutura física está referenciada em Harvey (2005).

11 O agrupamento dos setores em variáveis investigativas é de responsabilidade desta autora e tem por objetivo facilitar a apresentação e a análise dos dados. As quatro variáveis, com os respectivos setores agrupados são: a) Política social: desenvolvimento urbano e moradia, educação, investimento social, saúde, saneamento; b) Meio ambiente: meio Ambiente e desastre natural; c) Reforma do Estado: reforma e modernização do Estado; d) Projetos Econômicos e Infraestrutura: agricultura e desenvolvimento rural, ciência e tecnologia, comércio exterior, crédito e pré-investimento multissetor, desenvolvimento do setor privado, energia, indústria, mercado de capital, microempresa, tecnologia de informação e telecomunicação, transporte, turismo.

12 O contrato de empréstimo foi aprovado em 9 de julho de 2008 e assinado em 2 de abril de 2009 (BID, 2009a), sob o Empréstimo número 1998/OC-BR, Projeto número BR-L1065. Em alguns documentos da Prefeitura de Belém, aparece o nome Programa de Macrodrenagem da Bacia da Estrada Nova.

13 A Bacia daEstrada Novaé constituída de sete principais igarapés e/ ou canais, com extensão de cerca de $9,54 \mathrm{~km}^{2}$ e $72,70 \%$ do solo composto de áreas inundáveis.

14 Em conversa com técnicos que trabalham atualmente no Promaben, em Belém, foi identificado que: as obras em andamento estão localizadas na sub-bacia 1; até o mês de setembro de 2011, foram indenizadas pelo programa 146 famílias cujas residências foram avaliadas acima de $\mathrm{R} \$ 25$ mil; 55 famílias, cujas residências estão avaliadas abaixo desse valor, estão recebendo auxílio-moradia, equivalente a $\mathrm{R} \$ 450$, enquanto aguardam ser reassentadas para o Residencial Antônio Vinagre (Residencial Cabano). Para este residencial, está previsto o total de 110 unidades. Será construído um residencial (próximo ao Residencial Aluísio Chaves) para reassentar 320 famílias. Segundo informações dos técnicos do programa, além das taxas de água, luz e impostos, que serão incorporados à nova residência, as famílias terão que arcar com os custos de condomínio nos novos apartamentos, o que deverá encarecer o orçamento familiar.

15 O Projeto Orla compõe, juntamente com o Programa de Saneamento da Bacia da Estrada Nova, o "Projeto Portal da Amazônia", de responsabilidade da Prefeitura Municipal de Belém. A respeito da questão do embelezamento, diz a Prefeitura de Belém que as intervenções físicas (pistas, áreas de passeio, estacionamento e ciclovia, quadras de esporte, restaurantes etc.) serão feitas "nos moldes das orlas construídas nos grandes centros, como Recife e Rio de Janeiro. Com o projeto, a prefeitura pretende fazer com que Belém desponte definitivamente para o turismo com objetivo de gerar emprego e renda, aliado às outras obras que abriram algumas janelas para o rio, como a Estação das Docas, as Onze Janelas e o Mangal das Garças” (BELÉM, 2010, on-line).

16 O item orla tem a previsão de $23,5 \%$, do total de $\mathrm{R} \$ 532.450$ milhões, ou seja, a maior previsão de gastos em relação ao total da planilha de custos.

17 Enquanto isso, diz um especialista urbano do BID: "O banco tem identificado numerosas áreas de apoio intersetorial para melhoraro meio ambiente urbano e evitar problemas ambientais" (ROJAS, 2004, p. 60, tradução desta autora).

18 Um exemplo prático dessa processualidade: recentemente o presidente do BID (Luis Alberto Moreno) e a presidente do Brasil (Dilma Roussef) encontraram-se oficialmente pela primeira vez, para tratar da agenda de trabalho do banco no país. Os temas tratados foram, entre outros, o apoio do banco ao "Plano Brasil sem Miséria" e o financiamento para as cidades-sede da Copa do Mundo a ser realizada no Brasil em 2014, pois o "Banco deve investir até 2014 cerca de US $\$ 6$ bilhões em projetos de infraestrutura nestas cidades" (BID, 2011b, s/p).

19 Aparênciano sentido do método dialético, onde o fenômeno esconde a essência. 
Joana Valente Santana

joanavalente@ufpa.br

Doutorado em Serviço Social pela Universidade Fe-

deral do Rio de Janeiro (UFRJ)

Docente da Faculdade de Serviço Social e do Programa de Pós-Graduação em Serviço Social da Universidade Federal do Pará (UFPA)

\section{UFPA}

Cidade Universitária Prof. José da Silveira Netto Rua Augusto Corrêa, 1

Guamá

Belém - Pará

CEP: 66075-110 